\title{
Editorial for the CORDEX-CORE Experiment I Special Issue
}

\author{
Filippo Giorgi ${ }^{1}$ (D) Erika Coppola ${ }^{1} \cdot$ Claas Teichmann $^{2} \cdot$ Daniela Jacob $^{2}$
}

Published online: 4 August 2021

(c) The Author(s), under exclusive licence to Springer-Verlag GmbH Germany, part of Springer Nature 2021

\section{The CORDEX-CORE initiative}

The Coordinated Regional Downscaling Experiment (CORDEX, Giorgi et al. 2009; Jones et al. 2011a) is the main reference program for the climate downscaling community. During its first activities, CORDEX has resulted in the production of ensembles of projections over continental scale domains covering most land areas of the globe at an intermediate resolution of $\sim 50 \mathrm{~km}$ (e.g. Giorgi and Gutowski 2015), with the exception of the EURO-CORDEX (Jacob et al. 2013; Jacob et al. 2020) and MED-CORDEX (Ruti et al. 2016) programs for which higher resolution projections have been completed. However, one of the weaknesses of this first set of CORDEX projections is the heterogeneity in size and simulation protocol (e.g. choice of driving global climate model, GCM) of projections across different domains. For example, several tens of experiments are available for domains such as Europe, Africa, North America, East and South Asia, while only a few have been completed for, e.g., Australia and Central Asia. This has made it difficult to assess globally and in a consistent way the value of these downscaled projections.

The CORDEX-CORE (Coordinated Output for Regional Evaluations) initiative was thus launched in the mid 2010s (Gutowski et al. 2016) to address this problem and provide a homogeneous set of projections for all CORDEX domains using a core set of RCMs driven by a common set of GCMs using the same simulation protocol for each domain. User communities for two RCM systems participated to the first CORDEX-CORE experiment (hereafter referred to as CORDEX-CORE EXP-I), the RegCM4 (Giorgi et al. 2012) and REMO (Jacob et al. 2012).

Filippo Giorgi

giorgi@ictp.it

1 Earth System Physics Section, The Abdus Salam International Centre for Theoretical Physics (ICTP), Trieste, Italy

2 Climate Service Center Germany (GERICS), Hamburg, Germany
RegCM4 is the fourth generation version of the RegCM regional modeling system (Giorgi et al. 2012) developed at the Abdus Salam International Centre for Theoretical Physics (ICTP). It includes a hydrostatic dynamical core based on sigma-p vertical coordinates and multiple choices of different physics parameterizations (see Giorgi et al. 2012). The model includes multiple physics options and for each domain different schemes were selected based on preliminary experiments aimed at optimizing the model performance in terms of various temperature, precipitation, sea level pressure and wind metrics. The selected schemes are reported in Coppola et al. (2021) and for all simulations the model employs 23 unequally spaced vertical levels with higher density in the boundary layer.

REMO is a hydrostatic atmospheric model using hybrid vertical coordinates (Jacob et al. 2012; Remedio et al. 2019) developed at the Climate Service Center Germany (GERICS). It is based on the dynamics of the German Weather Service weather prediction model (Europa Modell) and the physics of the ECHAM 4.5 GCM. For all domains REMO the same physics schemes and 27 unequally spaced vertical levels (see Remedio et al. 2019). Only the values of some parameters within the schemes are adjusted for the specific domain conditions.

Nine domains were simulated for these first experiments (Giorgi et al. 2009): North, Central and South America, Europe, Africa, South Asia, East Asia, Southeast Asia and Australasia. They were chosen because they cover the most populated continental regions of the globe without a large overlap across domains. The model horizontal grid spacing is $25 \mathrm{~km}$ (or $0.22^{\circ}$ lat $\times$ lon), i.e. a resolution doubled compared with previous CORDEX simulations. The only exception is the European domain for which the horizontal grid spacing is $12.5 \mathrm{~km}$ (or $0.11^{\circ}$ lat $\times$ lon) following the EURO-CORDEX specifications (Jacob et al. 2020).

For each domain, six projections were carried out by each RCM, extending from 1975 to 2100 and including two greenhouse gas concentration scenarios, the low end RCP2.6 and the high end RCP8.5 (Moss et al. 2010), and three driving GCMs from the Coupled Model Intercomparison Project 
5 (CMIP5; Taylor et al. 2012): NOR-ESM1 (Bentsen et al. 2013), MPI-ESM (Giorgetta et al. 2013) and HadGEM2ES (Jones et al. 2011b). The choice was limited to three GCMs due to availability of computational and human resources and was based on two criteria. First, these GCMs are among the best performing over the CORDEX domains within the CMIP5 ensemble, (e.g. Elguindi et al. 2014; McSweeney et al. 2015) and second, they roughly span the range of global climate sensitivity of the CMIP5 ensemble, with HadGEM2-ES having a high sensitivity, MPI-ESM a medium sensitivity and NOR-ESM1 a low sensitivity. The overall goal was thus to use a minimum number of GCMs to approximately cover the range of global climate sensitivities in CMIP5 with well performing models. Two exceptions should be mentioned for the RegCM4 ensemble, i.e. HadGEM2-ES over the South Asia domain was replaced by MIROC5 (Watanabe et al. 2010) because it did not simulate well the South Asia monsoon, and NOR-ESM1 over the central America domain was replaced by GFDL-ESM2 (Dunne et al. 2012) in order to obtain a better simulation of tropical cyclones. These projections were also complemented with corresponding "perfect boundary condition" experiments with the two RCMs driven by the ERA-Interim reanalysis (Dee et al. 2011) for the period 1970-2000.

Time-dependent lateral boundary conditions for horizontal wind components, temperature, water vapor and surface pressure (or related variables used by the models) are provided at 6-hourly intervals. Sea surface temperature is also interpolated from the GCMs as a time varying lower boundary condition, while greenhouse gas concentrations in the RCMs are updated following observed values until 2005 and the selected scenarios from 2005 to 2100, same as done in the driving GCMs. Each RCM specifies its own constant land surface type distribution and background aerosol concentration. The output from all simulations was postprocessed according to the CORDEX specifications (https:// cordex.org) and is stored in the Earth System Grid Federation (ESGF) system, so that it is of public access.

\section{The SI papers}

The papers included in the SI represent the first analysis of the CORDEX-CORE EXP-I ensemble simulations. They generally consider multiple domains (with only a few exceptions) and focus on a wide range of topics, from the analysis of basic climatologies and different climate indices, to the investigation of specific regional phenomena and quantities of interest for impact applications. All papers are multi-authored by contributing members of the simulation and analysis teams coming from institutions in a number of countries. Also note that many of the selected topics were identified during a paper-writing workshop held at ICTP in the Spring of 2019, with the specific purpose of involving as many contributors as possible to the first analysis of the CORDEX-CORE EXP-I ensemble. In this regard, the SI was truly a community effort.

The SI starts with two papers presenting an overarching analysis of the full CORDEX-CORE EXP-I ensemble, including both RCMs and all domains. Teichmann et al. (2021) report on an assessment of the ensemble model performance in reproducing present day climatologies and mean climate change signals, while Coppola et al. (2021) present an analogous analysis for a range of extreme and hazard indices. Along the same lines, Evans et al. (2020) focus on the assessment of performance and change signals over the Australian region.

In all papers of the SI, within the scientific questions they address, comparisons between RCM and driving GCM signals are presented with the aim of identifying the added value of the RCM downscaling. However, the paper by Ciarlo et al. (2020) focuses specifically on this topic, and investigates a new distributed metric of added value based on daily precipitation intensity distributions of both present day and future climate. This new metric is of general use and is proposed as a standard practice to quantify the added value of RCM simulations.

A number of papers then focus on specific regional phenomena within the context of both present day and change signals: monsoons (Ashfaq et al 2020), ENSO teleconnections (Torres-Alavez et al. 2021a); environments conducive to the formation of severe thunderstorms (Glazer et al. 2020); low level jets (Torres-Alavez et al 2021b); southern hemisphere wintertime cyclonic activity (Reboita et al. 2020); tropical cyclones (Torrez-Alavez et al. 2021c); regional water budgets (Llopart et al 2021). In addition, Luna-Nino et al. (2021) focuses on the winter subtropical jet stream in the central America domain.

Finally, two papers are more oriented toward impact applications. Im et al. (2020) investigates the emergence of anthropogenically induced changes of heat stress-related variables and Sawadogo et al. (2020) focuses on changes in climatic indices relevant for renewable energy potential production over the African continent.

\section{Future developments}

The CORDEX-CORE EXP-I initiative was a huge community effort from the computational and human resources point of view, resulting in the production of several petabytes of data, which is now being used in various contexts, including the sixth assessment report of the Intergovernmental Panel on Climate Change (IPCC). The CORDEXCORE EXP-I dataset is indeed intended to be a community resource for the study of regional climate phenomena in a 
climate change context and for application to vulnerabilityimpacts-adaptation (VIA) assessment studies and climate service activities.

What are future developments of the CORDEX-CORE initiative? First, the EXP-I experiment can be augmented by the inclusions of runs with other RCM systems following the same simulation protocol, even if they are not carried out for all domains. The original aim of the CORDEX-CORE was to include a larger set of RCMs in order to better explore the uncertainty associated with the use of different models. This was evidently not possible from the resources point of view, but it is desirable that a broader RCM community is involved in future activities.

CMIP5 GCMs were used as driving models for the CORDEX-CORE EXP-I projections, since they were the only available when this initiative started. New and higher resolution GCM projections are now available from the CMIP6 initiative (Eyring et al. 2016; Gutowski et al. 2016), so that it would be important to enlarge the present ensembles with CMIP6-driven experiments.

In terms of model resolution, on the one hand it has been shown that a further doubling of grid spacing (order of $12.5 \mathrm{~km}$ or $0.11^{\circ}$ ) may provide significant added value compared to $25 \mathrm{~km}$ (e.g. Giorgi et al. 2016; Prein et al. 2016), and therefore this could be the next target for CORDEXCORE. On the other hand, the RCM community is rapidly moving towards convection-permitting model resolutions of a few km (e.g. Prein et al. 2015; Coppola et al. 2020; Ban et al. 2021; Pichelli et al. 2021). It is still not feasible to run ensembles of convection-permitting century long simulations over continental scale domains, however it may be possible to identify a few smaller regions of special interest for which such experiments may be feasible. All these issue are currently under discussion within the CORDEX community, so that the CORDEX-CORE initiative can remain a central resource for the climate modeling and climate service communities.

\section{References}

Ashfaq M, Cavazos T, Reboita MS, Torres-Alavez JA, Im E-S et al (2020) Robust late 21 st century shift in the regional monsoons in RegCM-CORDEX simulations. Clim Dyn. https://doi.org/10. 1007/s00382.020.05306.2

Ban N, Caillaud C, Coppola E et al (2021) The first multi-model ensemble of regional climate simulations at kilometer scale resolution. Part I: evaluation of precipitation. Clim Dyn. https://doi. org/10.1007/s00382-021-05708-w

Bentsen M, Bethke I, Debernard JD et al (2013) The Norwegian earth system model noresm1-m-part 1: description and basic evaluation of the physical climate. Geosci Mod Dev 6:687-720

Ciarlo JM, Coppola E, Fantini A, Giorgi F, Gao XJ et al (2020) A new spatially distributed Added value Index for Regional Climate Models: the EURO-CORDEX and the CORDEX-CORE highest resoluton ensembles. Clim Dyn. https://doi.org/10.1007/ s00382-020-05400-5

Coppola E, Sobolowski S, Pichelli E et al (2020) A first-of-its-kind multi-model convection permitting ensemble for investigating convective phenomena over Europe and the Mediterranean. Clim Dyn 55:3-34. https://doi.org/10.1007/s00382-018-4521-8

Coppola E, Raffele F, Giorgi F et al (2021) Climate hazard indices projections based on CORDEX-CORE, CMIP5, and CMIP6 ensembles. Clim Dyn. https://doi.org/10.1007/ s00382-021-05640-z

Dee DP, Uppala SM, Simmons AJ, Berrisford B, Poli P et al (2011) The ERA-Interim reanalysis: configuration and performance of the data assimilation system. Bull Roy Met Soc 137:553-597

Dunne JP, John JG, Adcroft AJ, Griffies SM, Hallberg SW et al (2012) GFDL's esm2 global coupled climate-carbon Earth System Model. Part I: physical formulation and baseline simulation characteristics. J Climate 25:6646-6665

Elguindi N, Giorgi F, Turuncoglu UU (2014) Assessment of CMIP5 global model simulations over the sub-set of CORDEX domains used in the Phase I CREMA Experiment. Clim Change. https:// doi.org/10.1007/S10584-013-0935-9

Evans PJ, Di Virgilio G, Hirsch AL, Hoffmann P, Remedio AR et al (2020) The CORDEX Australasia ensemble: evaluation and future projections. Clim Dyn. https://doi.org/10.1007/ s00382-020-054590

Eyring V, Bony S, Meehl GA, Senior CA, Stevens B et al (2016) Overview of the Coupled Model Intercomparison Project Phase 6 (CMIP6) experimantal design and organization. Geosci Model Dev 9:1937-1958

Giorgetta MA, Jungclaus J, Reick CH et al (2013) Climate and carbon cycle changes fom 1850 to 2100 in mpi-esm simulations for the coupled model intercomparison project Phase 5. J Adv Model Earth Syst 5:572-597

Giorgi F (2019) Thirty years of regional climate modeling: where are we and where are we going next? J Geophys Res Atmos 124:5696-5723

Giorgi F, Gutowski WJ (2015) Regional dynamical downscaling and the CORDEX initiative. Annu Rev Environ Resour 40:467-490

Giorgi F, Jones C, Asrar G (2009) Addressing climate information needs at the regional level: The CORDEX framework. WMO Bulletin 58:175-183

Giorgi F, Coppola E, Solmon F, Mariotti L et al (2012) RegCM4: model description and preliminary tests over multiple CORDEX domains. Clim Res 52:7-29

Giorgi F et al (2016) Enhanced summer convective rainfall at Alpine high elevations in response to climate warming. Nat Geosci 9:584-589

Glazer RH, Torres-Alavez JA, Coppola E, Giorgi F, Das S, Ashfaq M, Sines T (2020) Projected changes to severe thunderstorm environments as a result of 21 st century warming from RegCM CORDEX-CORE simulations. Clim Dyn. https://doi.org/10. 1007/s00382-020-05439-4

Gutowski WJ Jr, Giorgi F, Timbal B, Frigon A, Jacob D et al (2016) WCRP coordinated regional downscaling experiment (CORDEX): a diagnostic MIP for CMIP6. Geosci Model Dev 9:40874095. https://doi.org/10.5194/gmd-9-4087-2016

Im E-S, Thanh N-X, Qiu L, Ashfaq M, Gao XJ et al (2020) Emergence of robust anthropogenic increase of heat stress-related variables projected from CORDEX-CORE climate simulations. Clim Dyn. https://doi.org/10.1007/s00382-020-0539-w

Jacob D, Elizalde A, Haensler A, Hagemann S, Kumar P et al (2012) Assessing the transferability of the regional climate model REMO to different coordinated regional climate downscaling experiment (CORDEX) regions. Atmosphere 3:181-199. https://doi.org/10.3390/atmos3010181 
Jacob D et al (2013) EURO-CORDEX: new high-resolution climate change projections for European impact research. Reg Environ Change 14:563-578

Jacob D et al (2020) Regional climate downscaling over Europe: perspectives from the EURO-CORDEX community. Reg Env Change. https://doi.org/10.1007/s10113-020-01606-9

Jones C, Giorgi F, Asrar G (2011a) The coordinated regional downscaling experiment: CORDEX. An international downscaling link to CMIP5. CLIVAR Exchanges 16:34-40

Jones CD, Hughes JK, Bellouin N, Hardiman SC, Jones GS et al (2011b) The HadGEM2-ES implementation of CMIP5 centennial simulations. Geosci Model Dev 4(3):543-570. https://doi. org/10.5194/gmd-4-543-2011

Llopart M, Domingues LM, Torma C, Giorgi F, da Rocha PM et al (2021) Assessing changes in atmospheric water budget as drivers for precipitation change over two CORDEX-CORE domains. Clim Dyn. https://doi.org/10.1007/s00382-020-05539-1

Luna-Nino R, Cavazos T, Torres-Alavez JA, Giorgi F, Coppola E (2021) Interannual variability of boreal winter sub-tropical jet stream and teleconnections over the CORDEX-CAM domain during 1980-2010. Clim Dyn. https://doi.org/10.1007/ s00382-020-05509-7

McSweeney CF, Jones RG, Lee RW et al (2015) Selecting CMIP5 GCMs for downscaling over multiple regions. Clim Dyn 44:3237. https://doi.org/10.1007/s00382-014-2418-8

Moss RH et al (2010) The next generation of scenarios for climate change research and assessment. Nature 463:747-756

Pichelli E, Coppola E, Sobolowski S et al (2021) The first multi-model ensemble of regional climate simulations at $\mathrm{km}$-scale resolution. Part 2: historical and future simulations of precipitation. Clim Dyn. https://doi.org/10.1007/s00382-021-05657-4

Prein AF et al (2015) A review on regional convection permitting regional climate modeling: demonstrations, prospects and challenges. Rev Geophys 53:323-361

Prein AF et al (2016) Precipitation in the EURO-CORDEX 0.11 and 0.44 simulations: high resolution high benefits? Clim Dyn 46:383-412

Reboita MS, Reale M, da Rocha RP, Giorgi F, Giuliani G et al (2020) Future changes in the wintertime cyclonic activity over the
CORDEX-CORE Southern Hemisphere domains in a multi-model approach. Clim Dyn. https://doi.org/10.1007/s00382.020.05317.z

Remedio AR, Teichmann C, Buntemeyer L, Sieck K, Weber T et al (2019) Evaluation of new CORDEX simulations using an update Koppen-Trewartha climate classification. Atmosphere 10:726. https://doi.org/10.3390/atmos10110726

Ruti P et al (2016) The MED-CORDEX initiative for Mediterranean climate studies. Bull Am Meteorol Soc 97:1187-1208

Sawadogo W, Reboita MS, Aissatou F, da Rocha RP, Odoulami RC et al (2020) Current and future potential of solar and wind energy over Africa using the RegCM4 CORDEX-CORE ensemble. Clim Dyn. https://doi.org/10.1007/s00382-020-05377-1

Taylor KE, Stouffer RJ, Meehl GA (2012) An overview of CMIP5 and the experiment design. Bull Am Meteorol Soc 93:485-498

Teichmann C, Jacob D, Remedio AR, Remke T, Buntemeyer L et al (2021) Assessing mean climate change signals in the global CORDEX-CORE ensemble. Clim Dyn. https://doi.org/10.1007/ S00382-020-05494-X

Torres-Alavez JA, Giorgi F, Kucharski F, Coppola E (2021a) ENSO teleconnections in an ensemble of CORDEX-CORE regional simulations. Clim Dyn. https://doi.org/10.1007/s00382-020-05594-8

Torres-Alavez JA, Das S, Corrales-Suastegui A, Coppola E, Giorgi F (2021b) Future projections in the climatology of low-level jets from CORDEX-CORE simulations. Clim Dyn. https://doi.org/10. 1007/s00382-021-05671-6

Torres-Alavez JA, Glazer R, Giorgi F, Coppola E, Gao XJ (2021c) Future projections in tropical cyclone activity over multiple CORDEX domains from RegCM4 CORDEX-CORE simulations. Clim Dyn. https://doi.org/10.1007/s00382-021-05828-6

Watanabe M, Suzuki T, O'ishi R, Komuro Y, Watanabe S et al (2010) Improved climate simulation by MIROC5: mean states, variability and climate sensitivity. J Clim 23:6312-6335

Publisher's Note Springer Nature remains neutral with regard to jurisdictional claims in published maps and institutional affiliations. 